\title{
AN EPIDEMIOLOGICAL STUDY OF HYPERTENSION AMONG THE ADULT POPULATION IN THE URBAN SLUMS OF GUWAHATI CITY, ASSAM
}

\author{
Priyanka Das ${ }^{1}$, Achyut Chandra Baishya ${ }^{2}$ \\ ${ }^{1}$ Assistant Professor, Department of Community Medicine, Fakhruddin Ali Ahmed Medical College, Barpeta, Assam. \\ 2 Professor and HOD, Department of Community Medicine, Tezpur Medical College, Assam.
}

ABSTRACT
BACKGROUND
Hypertension is a major public health problem worldwide. The migration and settlement of rural population to cities in search
of earning avenues exposes them to several adverse environmental influences and alterations in lifestyle. There is a strong co-
relation between changing lifestyle factors and increase in prevalence of hypertension in India. Therefore, it is important to find out
the prevalence and identify the risk factors of hypertension in the urban slums of Guwahati city, Assam.

\section{OBJECTIVES}

To assess the prevalence of hypertension and identify the associated risk factors among the adult population in the urban slums of Guwahati city, Assam.

\section{METHODOLOGY}

A cross-sectional study was conducted among 810 adults aged 18 years and above with detailed history followed by physical examination to evaluate various risk factors associated with hypertension. Data was analysed by using percentage for prevalence and Chi-square test was used to find out the association.

\section{RESULTS}

The overall prevalence of hypertension was $12.1 \%$. The prevalence of hypertension among males and females was $12.98 \%$ and $11.27 \%$, respectively. Factors such as age, occupation, tobacco use, salt consumption, family history of hypertension and BMI showed a statistically significant association.

\section{CONCLUSION}

The study shows a high prevalence of hypertension in the slum areas. The non-communicable disease strategy taking hypertension and cardiovascular diseases into consideration with extensive IEC activities regarding hypertension and its risk factors should be given priority in slum areas. Also opportunity for detection in individuals seeking health care and periodic screening of healthy individuals for early diagnosis and management should be done in these areas.

\section{KEYWORDS}

Hypertension, Prevalence, Risk Factors, Urban Slums.

HOW TO CITE THIS ARTICLE: Das P, Baishya AC. An epidemiological study of hypertension among the adult population in the urban slums of Guwahati city, Assam. J. Evolution Med. Dent. Sci. 2016;5(72):5261-5264, DOI: 10.14260/jemds/2016/1192

\begin{abstract}
INTRODUCTION
Hypertension, the commonest cardiovascular disorder, has become an important public health problem worldwide. Overall $26.4 \%$ (972 million) of the adult world population was estimated to have hypertension in the year 2000 (based on a pooled analysis of available national and regional data by Kearney et al), a figure that is projected to increase to $29.2 \%$ ( 1.56 billion) by the year 2025.1 It is the most important risk factor in terms of attributable mortality worldwide. Estimates from the World Health Organisation Global Burden of Disease Study (WHO GBDS, 2005) indicate that approximately 13\% of global mortality may be attributed to high blood pressure ${ }^{2}$ translating into more than 7 million deaths per year.
\end{abstract}

Financial or Other, Competing Interest: None.

Submission 04-07-2016, Peer Review 25-08-2016,

Acceptance 31-08-2016, Published 07-09-2016.

Corresponding Author:

Dr. Priyanka Das,

Department of Community Medicine,

Fakhruddin Ali Ahmed Medical College and Hospital,

Jotigaon, Jania Road,

Barpeta District-Barpeta-781302, Assam.

E-mail: drpriyankadas4@gmail.com

DOI: $10.14260 /$ jemds/2016/1192
In terms of DALYs an indicator for loss of healthy life, high blood pressure is the second major cause of disability worldwide 3 next to childhood underweight (Lopez et al 2006). Developed countries are considering it as a leading cause of death, but even developing countries do not lag behind in being affected by it. The report by Kearney et al, also stated that the estimated number of hypertensives in developing countries outweighed that of developed countries by almost two-fold (639 million in developing countries versus 333 million in developed countries). ${ }^{1}$

Hypertension is emerging as a major public health problem in India and is more prevalent among urban people compared to those of rural area (Gupta R, 1997). ${ }^{4}$ Pooling of epidemiological studies shows that hypertension is present in $25 \%$ urban and $10 \%$ rural subjects in India. Studies conducted in some urban slums in India have shown a high prevalence of hypertension. In this context, there is a need for community level data in urban slums in this part of the country. Keeping in view the above facts, the study was conducted to assess the prevalence of hypertension and identify the associated risk factors among the adult population in the urban slums of Guwahati city, Assam. 


\section{MATERIAL AND METHODS}

The study is a community based cross-sectional study conducted from November 2009 to October 2010 among adult population 18 years and above residing in the urban slums of Guwahati city, Assam. The sample size was calculated taking the prevalence of hypertension as $11 \% .{ }^{5}$ The sample size for the present study was worked out to be 810 applying the formula $-\mathrm{N}=4 \mathrm{PQ} / \mathrm{L}^{2}$ accepting $20 \%$ permissible error.

Out of 85 slums in the city, the slums with less than 100 households were clubbed together and considered as one unit, after which the total number of slums came out to be 70 . Considering $10 \%$ of the 70 slums, i.e. 7 slums were selected by simple random sampling technique using random number table. Total number of households in the selected slums was 1867.

Assuming at least two adults of 18 years and above in each household, minimum number of households required to obtain the sample size of 810 was calculated out to be 405 . Number of households for each slum was then selected by applying households proportionate to size allocation method. Data was collected by using a pre-designed, pre-tested interview schedule followed by physical examination (Using mercury sphygmomanometer, stethoscope, weighing machine and measuring tape). The respondents were carefully briefed prior to the commencement of the field work regarding purpose of the study so as to get their full co-operation during the study period, so that the information could be obtained by the investigator in optimum time. The interviews were conducted by house-to-house visit. Pregnant women, acutely ill individuals and bedridden elderly were excluded from the study.

The initial part of the interview dealt with the demographic characteristics and socio-economic status of the family. Then individual information of the respondents like age, sex, marital status, educational qualification, occupation, tobacco use, alcohol consumption, type of diet, salt consumption, fruit consumption, physical activity, family history of hypertension, self-reported history of suffering from hypertension, etc. was collected. This was followed by physical measurements like weight, height, BMI and measurement of blood pressure. JNC 7 guideline was used to define hypertension and/or current treatment with antihypertensive drugs. ${ }^{6}$

\section{Ethical Consideration}

Clearance was obtained from Institutional Ethics Committee prior to initiation of the study.

\section{RESULTS AND OBSERVATIONS}

The study was conducted among 810 adult respondents, out of which 393 (48.52\%) were males and 417 (51.48\%) were females. Most of them belonged to general caste (55.19\%) and $68.77 \%$ were Hindu by religion; $93.58 \%$ were married; $88.15 \%$ belonged to nuclear families; $46.1 \%$ were illiterate. Majority of them $(41.36 \%)$ earned their living as daily wage earners; $47.8 \%$ of respondents belonged to social class IV (BG Prasad classification. ${ }^{7}$ ) The study shows that hypertension was prevalent among $12.1 \%$ of the adults residing in the urban slums. Prevalence of hypertension was slightly higher among males $(12.89 \%)$ compared to females $(11.27 \%)$ though the difference was statistically not significant. Prevalence of hypertension increased with increasing age. Factors such as age, occupation, presence of family history of hypertension, tobacco consumption, BMI has shown significant association in this study (Table 1 and Table 2).

\begin{tabular}{|c|c|c|c|c|c|c|}
\hline \multirow{3}{*}{ Variable } & \multirow{3}{*}{ Sub-Groups } & \multicolumn{4}{|c|}{ Groups } & \multirow{3}{*}{ P-value } \\
\hline & & \multicolumn{2}{|c|}{$\begin{array}{c}\text { Non-Hypertensive } \\
(n=712)\end{array}$} & \multicolumn{2}{|c|}{$\begin{array}{c}\text { Hypertensive } \\
(n=98)\end{array}$} & \\
\hline & & No. & $\%$ & No. & $\%$ & \\
\hline \multirow{6}{*}{ Age } & $18-27$ & 175 & 98.87 & 2 & 1.13 & \multirow{6}{*}{$\mathrm{P}<0.001$} \\
\hline & $28-37$ & 194 & 95.57 & 9 & 4.43 & \\
\hline & $38-47$ & 193 & 89.35 & 23 & 10.65 & \\
\hline & $48-57$ & 123 & 75.46 & 40 & 24.54 & \\
\hline & $58-67$ & 24 & 57.14 & 18 & 42.86 & \\
\hline & $>68$ & 3 & 33.33 & 6 & 66.67 & \\
\hline \multirow{2}{*}{ Sex } & Male & 342 & 87.02 & 51 & 12.98 & \multirow{2}{*}{$\mathrm{P}>0.05$} \\
\hline & Female & 370 & 88.73 & 47 & 11.27 & \\
\hline \multirow{4}{*}{ Caste } & General & 398 & 89.04 & 49 & 10.96 & \multirow{4}{*}{$P>0.05$} \\
\hline & $\mathrm{OBC}$ & 135 & 84.91 & 24 & 15.09 & \\
\hline & $\mathrm{SC}$ & 171 & 87.24 & 25 & 12.76 & \\
\hline & ST & 8 & 100 & 0 & 0 & \\
\hline \multirow{2}{*}{ Religion } & Hindu & 494 & 88.69 & 63 & 11.31 & \multirow{2}{*}{$\mathrm{P}>0.05$} \\
\hline & Islam & 218 & 86.17 & 35 & 13.83 & \\
\hline \multirow{2}{*}{ Type of Family } & Nuclear & 627 & 87.82 & 87 & 12.18 & \multirow{2}{*}{$\mathrm{P}>0.05$} \\
\hline & Joint & 85 & 88.54 & 11 & 11.46 & \\
\hline \multirow{6}{*}{$\begin{array}{l}\text { Educational } \\
\text { Qualification }\end{array}$} & Illiterate & 332 & 88.77 & 42 & 11.23 & \multirow{6}{*}{$\mathrm{P}>0.05$} \\
\hline & Primary School & 200 & 86.21 & 32 & 13.79 & \\
\hline & High School & 123 & 85.42 & 21 & 14.58 & \\
\hline & HSLC Passed & 36 & 94.74 & 2 & 5.26 & \\
\hline & HS Passed & 15 & 93.75 & 1 & 6.25 & \\
\hline & Graduate \& Above & 6 & 100 & 0 & 0 & \\
\hline \multirow{4}{*}{ Occupation } & Daily Wage Earner & 316 & 94.33 & 19 & 5.67 & \multirow{4}{*}{$\mathrm{P}<0.001$} \\
\hline & Skilled Worker & 48 & 78.69 & 13 & 21.31 & \\
\hline & Own Business & 72 & 80.90 & 17 & 19.10 & \\
\hline & Service & 10 & 90.91 & 1 & 9.09 & \\
\hline
\end{tabular}




\begin{tabular}{|c|c|c|c|c|c|c|}
\hline & Unemployed & 14 & 93.33 & 1 & 6.67 & \\
\hline & Housewife & 244 & 83.85 & 47 & 16.15 & \\
\hline & Student & 8 & 100 & 0 & 0 & \\
\hline \multirow{5}{*}{ Social Class } & $\mathrm{I}$ & 0 & 0 & 0 & 0 & \multirow{5}{*}{$\mathrm{P}>0.05$} \\
\hline & II & 66 & 84.62 & 12 & 15.38 & \\
\hline & III & 237 & 84.95 & 42 & 15.05 & \\
\hline & IV & 348 & 89.92 & 39 & 10.08 & \\
\hline & $\mathrm{V}$ & 61 & 92.42 & 5 & 7.58 & \\
\hline
\end{tabular}

\begin{tabular}{|c|c|c|c|c|c|c|}
\hline \multirow{3}{*}{ Variable } & \multirow{3}{*}{ Sub-Groups } & \multicolumn{4}{|c|}{ Groups } & \multirow{3}{*}{ P-Value } \\
\hline & & \multicolumn{2}{|c|}{$\begin{array}{c}\text { Non-Hypertensive } \\
\text { (n= 712) }\end{array}$} & \multicolumn{2}{|c|}{$\begin{array}{l}\text { Hypertensive } \\
(n=98)\end{array}$} & \\
\hline & & No. & $\%$ & No. & $\%$ & \\
\hline \multirow{2}{*}{ Type of Diet } & Vegetarian & 95 & 91.35 & 9 & 8.65 & \multirow{2}{*}{$\mathrm{P}>0.05$} \\
\hline & Non-Vegetarian & 617 & 87.39 & 89 & 12.61 & \\
\hline \multirow{2}{*}{ Extra Salt Intake } & Yes & 624 & 87.39 & 90 & 12.61 & \multirow{2}{*}{$\mathrm{P}>0.05$} \\
\hline & No & 88 & 91.67 & 8 & 8.33 & \\
\hline \multirow{4}{*}{ Fruit Consumption } & Regularly (3-4 times/week) & 33 & 91.67 & 3 & 8.33 & \multirow{4}{*}{$\mathrm{P}>0.05$} \\
\hline & Sometimes (1-2 times/week) & 100 & 92.60 & 8 & 7.40 & \\
\hline & Occasionally (1-3 times/month) & 496 & 86.71 & 76 & 13.29 & \\
\hline & Never & 83 & 88.30 & 11 & 11.70 & \\
\hline \multirow{2}{*}{ Tobacco Use } & User & 376 & 84.49 & 69 & 15.51 & \multirow{2}{*}{$\mathrm{P}<0.01$} \\
\hline & Non-User & 336 & 92.05 & 29 & 7.95 & \\
\hline \multirow{2}{*}{ Alcohol Use } & User & 192 & 84.96 & 34 & 15.04 & \multirow{2}{*}{$\mathrm{P}>0.05$} \\
\hline & Non-User & 520 & 89.04 & 64 & 10.96 & \\
\hline \multirow{3}{*}{ Physical Activity } & Sedentary & 412 & 88.41 & 54 & 11.59 & \multirow{3}{*}{$\mathrm{P}>0.05$} \\
\hline & Moderate & 219 & 85.88 & 36 & 14.12 & \\
\hline & Heavy & 81 & 91.01 & 8 & 8.99 & \\
\hline \multirow{2}{*}{ Family History of Hypertension } & Present & 58 & 61.70 & 36 & 38.30 & \multirow{2}{*}{$\mathrm{P}<0.001$} \\
\hline & Absent & 654 & 91.34 & 62 & 8.66 & \\
\hline \multirow{4}{*}{ BMI Category } & Underweight & 108 & 90.75 & 11 & 9.24 & \multirow{4}{*}{$\mathrm{P}<0.05$} \\
\hline & Normal & 541 & 89.13 & 66 & 10.87 & \\
\hline & Pre-Obese & 47 & 81.03 & 11 & 18.97 & \\
\hline & Obese & 16 & 61.54 & 10 & 38.46 & \\
\hline
\end{tabular}

\section{DISCUSSION}

In this study conducted, among 810 adult participants prevalence of hypertension was found to be $12.1 \%$. Studies conducted in similar settings among adults by Misra et $\mathrm{al}^{8}$ and Sahu $\mathrm{T}$ et $\mathrm{al}^{5}$ show comparable prevalence.

$12.98 \%$ of the male respondents and $11.27 \%$ of the female respondents were hypertensive. Higher prevalence of hypertension among males as compared to females have also been reported from other studies by Reddy S S and Prabhu G $\mathrm{R}(2005),{ }^{9}$ Sahu T et al (2005), ${ }^{5}$ Yadav $S$ et al (2007) ${ }^{10}$ and Chandwani $\mathrm{H}$ et al (2010). ${ }^{11}$ The difference was however statistically significant in all the studies except by Reddy S S and Prabhu G R (2005), which is statistically not significant comparable to this study. Statistically significant association of increasing age with hypertension has also been shown by studies conducted by various workers from different parts of the country (Haldiya K R et al, 2007),12 Vimala A et al (2009) ${ }^{13}$ and Mandal P K et al (2010). ${ }^{14}$ Other proven risk factors that have shown association with hypertension in this study include tobacco use, presence of family history of hypertension and BMI.

\section{CONCLUSION AND RECOMMENDATIONS}

The study shows that $12.1 \%$ of the adults in the urban slums were hypertensive which indicates the magnitude of the problem. Risk factors such as age, occupation, tobacco consumption, presence of family history of hypertension, BMI has shown significant association with hypertension. However, further large scale studies are needed taking into consideration more and in-depth exploration of the variables among the slum dwellers, which would help in planning strategies for prevention of hypertension in such population. Due to high prevalence of hypertension and presence of the risk factors, there is an urgent need to create awareness among the people residing in these slums regarding hypertension, its risk factors, symptoms, complications and also its preventable and curable nature so that they can adopt modification of their lifestyles for preventing the condition and seeking medical care at the earliest when needed.

\section{Strengths and Limitations of the Study}

The strengths of this study are that this study provides information regarding hypertension among slum dwellers in this part of the country, which to our knowledge have not been assessed so far. Standardised methods have been used to take the blood pressure readings using mercury sphygmomanometer. Limitations of the study were that a person was labelled as hypertensive based on average of two readings taken during a onetime visit to a slum, which may overestimate the prevalence of hypertension. As the study is a cross-sectional study, no follow-up measurements of blood pressure could be done. However, those labelled as hypertensive based on the readings were advised to visit any accessible health facility for further assessment of blood pressure at a later date. 


\section{REFERENCES}

1. Kearney PM, Whelton M, Reynolds K, et al. Global burden of hypertension: analysis of worldwide data. Lancet 2005;365(9455):217-23.

2. Murray CJ, Lopez AD. Alternative projections of mortality and disability by cause 1990-2020. Global burden of disease study. Lancet 1997;349(9064):1498-504.

3. Lopez AD, Mathers CD, Ezzati M, et al. Global and regional burden of disease and risk factors, 2001: systematic analysis of population health data. Lancet 2006;367(9524):1747-57.

4. Gupta R. Meta-analysis of prevalence of hypertension in India. Indian Heart J 1997;49(1):43-8.

5. Sahu T, Patnaik L, Sahani NC, et al. A study on hypertension in urban slum of Brahmapur, Orissa. Journal Community Medicine 2007;3(1):1-10.

6. The sixth report of the Joint National Committee on prevention, detection, evaluation and treatment of high blood pressure (JNC VI): NIH Publication No. 98-4080. Arch Intern Med 1997;157(21):2413-46.

7. Bhalwar R. Textbook of public health and community medicine. $1^{\text {st }}$ edn. Pune, India: Department of Community Medicine, AFMC 2009:612.

8. Misra A, Pandey RM, Devi JR, et al. High prevalence of diabetes, obesity and dyslipidaemia in urban slum population of northern India. Int J Obes Relat Metab Disord 2001;25(11):1722-9.
9. Reddy SS, Prabhu GR. Prevalence and risk factors of hypertension in adults in an urban slum, Tirupati, AP. Indian Journal Community Medicine 2005;30(3):84-6.

10. Yadav G, Chaturvedi S, Grover VL. Prevalence, awareness, treatment and control of hypertension among the elderly in a resettlement colony of Delhi. Indian Heart J 2008; 60(4):313-7.

11. Chandwani H, Pandor J, Jivarajani $P$, et al. Prevalence and correlates of hypertension among adults in the urban area of Jamnagar, Gujarat, India. Electronic Physician 2010;2:52-9.

12. Haldiya KR, Mathur ML, Sachdev R. Lifestyle-related risk factors for cardiovascular disease in a desert population of India. Current Science 2010;99(2):190-5.

13. Vimala A, Ranji SA, Jyosna MT, et al. The prevalence, risk factors and awareness of hypertension in an urban population of Kerala (South India). Saudi J Kidney Dis Transpl 2009;20(4):685-9.

14. Mandal PK, Roy AKS, Chatterjee C, et al. Burden of hypertension and its risk factors in an urban community of India: are we aware and concerned? Sudanese Journal Public Health 2010;5(3):130-5. 